\title{
An ESL Motivations Assessment for a Community-Based ESL Programme
}

\author{
Li Chuang Paper
}

This paper concerns an ESL motivations assessment of adult Chinese learners at Chinese Information and Community Services (CICS). 512 ESL learners participated in the survey. The findings of the survey are as follows: (1) The motives of adult Chinese immigrants attending ESL classes include linguistic needs, basic skills, cultural awareness, social interaction, and writing resumés. (2) There are no significant differences in perceived motivations according to age, education level, and length of stay in Canada; however, there are slight differences among a

\begin{abstract}
few indicators. (3) The implications to ESL teaching are that a) teaching objectives at the CICS of Metropolitan Toronto should include both the teaching of English and Canadian culture; b) the teaching of English should focus on language needed for conducting everyday life and social interaction; c) all four language skills (speaking, listening, reading, and writing) should be taught at the same time with more emphasis on the first three skills; d) pronunciation and vocabulary teaching is also necessary.
\end{abstract}

Recent developments in language teaching include interest in language teaching objectives, language content, and curriculum design (Stern 1983). Curriculum design, especially its content and objectives, should meet learners' needs. Meeting learners' needs is particularly important in the adult learning situation. Brundage and Mackeracher (1980: 106) write that "success in satisfying needs and reaching established objectives becomes a reinforcer for the changes already made and a motive for further learning." One method for eliciting learners' needs is through a motivation assessment.

Several studies have been done in ESL motivations assessment (Anisfeld and Lambert 1961; Lambert et al 1972; Gardner and Lambert 1972; Clément et al 1977; Ostler 1980; Beaty and Chan 1984; Sun 1987). The subjects of these studies were either high school students or adults in formal educational institutions. None of the studies assesses adult ESL motivations in nonformal educational institutions. The lack of research in assessing ESL motivations of adult learners in community-based programmes makes it difficult for ESL adult educators to plan the curriculum or teach this particular group of learners. It is hoped that the results and suggestions made in this study will be of assistance in these regards. 


\section{Purpose of Study}

The purpose of this study is to assess the ESL motivations of adult Chinese immigrants in a particular nonformal educational institution: Chinese Information and Community Services (CICS) of Metropolitan Toronto. The study seeks to answer the following questions: (1) What motivates adult Chinese immigrants attending ESL classes? (2) Do perceived motivations differ according to age, education level, and length of stay in Canada? (3) What are the implications of the results of this study for ESL teaching?

\section{Method}

\section{Chinese Information and Community Services}

The survey was conducted among learners at the CICS in the fall of 1988. The agency has two locations: Toronto and Scarborough. The agency provides services such as information and referral, counselling, ESL training programmes, etc., to all the Chinese-speaking people in Metro Toronto and vicinity.

\section{Participants}

Of 580 learners in the CICS' ESL classes, 570 participated in the survey, resulting in 512 usable or partially usable responses. Among the 512 surveyed, 379 were female and 129 male. 377 were from Hong Kong, 40 from China, 33 from Southeast Asia, and the remainder from India, Taiwan, South and Central America, Mauritius, and France. The participants ranged in age from $17-80(44 \%$ were $60+, 38 \%$ between the age of $45-59,14 \%$ between the age of $30-44$, and $3 \%$ between the age of 17-29).

\section{Variables}

Presently there is no generally accepted definition for "motivation" (Kidd 1959; Brundage and Mackeracher 1980; Wlodkowski 1985). Consequently, it is difficult to determine appropriate variables for assessing adult learners' motivations in second language learning. Moreover, the variables used by Gardner and Lambert (1972), Schumann (1975), and Clément et al (1977) may not necessarily be applicable to adult second language learners in nonformal educational institutions.

The writer decided, therefore, to utilize different variables to assess adult Chinese learners' motivations. The variables used in the survey consisted of linguistic needs, basic skills, cultural awareness, social interaction, and employment opportunities and advancement. 


\section{Procedures}

A survey kit which included a sheet explaining the purpose of the survey as well as procedures for conducting the survey, a data sheet for the instructor to fill out, a copy of the questionnaire in Chinese and English, and questionnaire (in Chinese) for the participants, was given to the ESL instructors by the ESL coordinator at CICS.

Chinese questionnaires were distributed to the learners and collected as soon as they finished. The questionnaire was divided into two parts: Personal data and Motivations for Studying English (see Appendix for the latter).

Because of their limited previous educational background, the participants were asked to rank their choices on a simple 3-point scale, according to the degree of importance to their ESL learning, rather than a 5-point scale. The 3-point scale was as follows: $1=$ "important", $2=$ "somewhat important", and $3=$ "not important". The numbers were changed as follows: 2 = "important", 1 = "somewhat important", and $0=$ "not important" for descriptive analysis. For interpretative analysis, the writer used even numerical distribution to provide a 5-value scale (see Table 2).

Due to a mistake made by the writer, the "grammar" indicator which was on the English version of the questionnaire was omitted from the Chinese version. As a result, the survey does not indicate the learners' interest in the learning of grammar.

\section{Results and Discussion}

\section{General}

Table 1 displays, in descending order, the group mean of the five variables: linguistic needs, basic skills, cultural awareness, social interaction, and employment and advancement. Linguistic needs received the highest mean of 1.7 while employment and advancement received the lowest of 0.9 .

Table 2 indicates the rank order, descending by mean, of the perceived motivations of adult Chinese ESL learners. The response for speaking, listening, reading, pronunciation, making phone calls, riding public transportation, shopping, seeking help, banking was "very important." This is not accidental given the fact that the group studied were immigrants. For immigrants, their primary motives in learning a second language is associated with their immediate needs: knowing the language and the basic skills required to function in the new society; i.e., survival skills.

The value for acquiring vocabulary, writing skill, using postal service, filling out forms, writing resumés, watching TV or movies, listening to radio, reading newspapers, learning about Canada, knowing Canadian fes- 


\section{A. LINGUISTIC NEEDS}

$\underline{\text { mean }}$ group mean
1. speaking
1.9
2. listening
1.9
3 . reading
1.7
4. writing
1.4
5. vocabulary
1.6
6. pronunciation
1.7

B. BASIC SKILLS

1. ride public trans.

2. shopping

1.8

3. banking

1.8

4. postal system

1.7

1.6

5. seek help

6. phone calls

7. forms

8. travel on own

1.5

9. $\mathrm{TV}$, radio, movies

1.5

10. newspapers

1.2

C. CULTURAL AWARENESS

1. learn about Canada

2. friends with Canadians

1.4

3. Canadian festivals

1.4

4. Canadian customs

1.4

D. SOCIAL INTERACTION

1. children

1.4

2. neighbours

1.6

3. parties

1.1

4. visit Canadians

1.0

E. EMPLOYMENT AND ADVANCEMENT

1. find job

1.0

2. advance in job

0.8

3. secondary education

0.5

4. make more money

0.8

4. resumé

1.4

GRAND MEAN 
Table 2

Survey Analysis: RANK ORDER (descending by mean)

I. VERY IMPORTANT (mean range $2.0-1.7$ )

$\begin{array}{ll}\text { speaking } & 1.9 \\ \text { listening } & 1.9 \\ \text { phone calls } & 1.9 \\ \text { ride public trans. } & 1.8 \\ \text { shopping } & 1.8 \\ \text { seek help } & 1.8 \\ \text { reading } & 1.7 \\ \text { pronunciation } & 1.7 \\ \text { banking } & 1.7\end{array}$

II. IMPORTANT (mean range $1.6-1.3$ )

$\begin{array}{ll}\text { vocabulary } & 1.6 \\ \text { postal system } & 1.6 \\ \text { forms } & 1.6 \\ \text { learn about Canada } & 1.6 \\ \text { neighbours } & 1.6 \\ \text { travel on own } & \underline{1.5} \\ \text { TV, radio, movies } & \underline{1.5} \\ \text { writing } & 1.4 \\ \text { friends with Canadians } & 1.4 \\ \text { Canadian festivals } & 1.4 \\ \text { Canadian customs } & 1.4 \\ \text { children } & 1.4 \\ \text { resumé } & \end{array}$

III. MODERATELY IMPORTANT (mean range $1.2-0.8$

$\begin{array}{ll}\text { newspapers } & 1.2 \\ \text { parties } & 1.1 \\ \text { visit Canadians } & 1.0 \\ \text { find job } & 1.0 \\ \text { advance in job } & 0.8 \\ \text { make more money } & 0.8\end{array}$

IV. SLIGHTLY IMPORTANT (mean range $0.7-0.4$ )

secondary education $\quad 0.5$

V. NOT IMPORTANT (mean range $0.3-0.0$ )

none 
tivals and customs, making friends with Canadians, travelling independently, and talking-to children, grandchildren, workmates, and neighbours-was "important." The response demonstrates that the secondary motives of learning English consists of linguistic needs such as vocabulary and writing, learning culture, ability to interact socially, and a job related indicator-writing resumés.

Reading newspapers, conversing at parties, visiting Canadians, advancing in and finding a job, and making more money were considered as only "moderately important" to adult Chinese ESL learners. In Metro Toronto, there is a large Chinese community and there are more than ten Chinese newspapers available to provide domestic and international news. Hence, the need for reading English language newspapers is not of primary importance. Conversing at parties and visiting Canadians for socialization are not highly important since (1) most of the Chinese assessed have their families or relatives here; thus, there is no need to seek others for social interaction; (2) for those who did not have families or relatives here, various Chinese organizations and associations, religious organizations, etc., provide opportunities to befriend other Chinese; and (3) due to linguistic and cultural barriers, it is difficult to socialize with other Canadians.

The participants also demonstrated a low interest in employment and advancement. This was probably related to the population studied. The majority of the participants (82\%) were over 45 years of age and, it can be assumed, they were less concerned about employment and advancement. Meanwhile, $82 \%$ of the respondents had less than Grade 10 education and would probably not be interested in pursuing post-secondary education.

\section{Residence in Canada}

There was no significant difference in regard to the length of stay (see Table 3) and motivation to learn English for speaking, listening, vocabulary, pronunciation, riding public transportation, shopping, banking, using postal system, seeking help, making phone calls, filling out forms, travelling on own, watching TV or movies, listening to radio, learning about Canada, making friends with Canadians, knowing Canadian festivals and customs, talking to neighbours, attending a college or university, and writing resumés. For example, speaking was considered very important to all the participants regardless of their duration of stay.

Reading and writing skills, reading newspapers, talking to children and grandchildren, finding and advancing in jobs, making more money, conversing at parties, and visiting Canadians were related to length of stay in Canada. These motives or needs decreased as the length of stay increased, 
Table 3

Survey Analysis-selection criteria: Residence in Canada

\begin{tabular}{llccccccc}
\multirow{3}{*}{ number } & months & $\mathrm{T}: 510$ & $\frac{1-6}{59}$ & $\frac{7-12}{48}$ & $\frac{13-24}{88}$ & $\frac{25-60}{180}$ & $\frac{61-120}{95}$ & $\frac{121+}{40}$ \\
& percent & $12 \%$ & $9 \%$ & $17 \%$ & $35 \%$ & $19 \%$ & $8 \%$
\end{tabular}

A. LINGUISTIC NEEDS
1. speaking
2. listening
3 . reading
4. writing
5. vocabulary
6. pronunciation

B. BASIC SKILLS

1. ride public trans.

2. shopping

3. banking

4. postal system

5. seek help

6. phone calls

7. forms

8. travel on own

9. $\mathrm{TV}$, radio, movies

10. newspapers

C. CULTURAL AWARENESS
1. learn about Canada
2. friends with Canadians
3. Canadian festivals
4. Canadian customs

D. SOCIAL INTERACTION
1. children
2. neighbours
3. parties
4. visit Canadians

$\begin{array}{llllll}1.2 & 1.3 & 1.6 & 1.4 & 1.6 & 1.4 \\ 1.6 & 1.5 & 1.6 & 1.6 & 1.5 & 1.6 \\ 1.3 & 1.0 & 1.2 & 1.0 & 0.9 & 1.3 \\ 1.2 & 1.1 & 1.2 & 0.9 & 0.9 & 1.2\end{array}$

2.

2.0

1.8

1.6

1.6

1.

$\begin{array}{ll}2.0 & 2.0\end{array}$

1.9

$1.9 \quad 1.9$

$2.0 \quad 2.0$

1.9

$1.9 \quad 1.9$

$1.7 \quad 1.8$

$\begin{array}{lll}1.6 & 1.6 & 1.6\end{array}$

$\begin{array}{lllll}1.6 & 1.6 & 1.3 & 1.2 & 1.2\end{array}$

$\begin{array}{llllll}1.6 & 1.8 & 1.7 & 1.6 & 1.4 & 1.5\end{array}$

$\begin{array}{llllll}1.6 & 1.7 & 1.8 & 1.7 & 1.6 & 1.6\end{array}$

$\begin{array}{llllll}1.8 & 1.9 & 1.8 & 1.8 & 1.7 & 1.7 \\ 1.8 & 1.9 & 1.7 & 1.8 & 1.7 & 1.8 \\ 1.8 & 1.8 & 1.8 & 1.7 & 1.5 & 1.8 \\ 1.6 & 1.6 & 1.6 & 1.6 & 1.5 & 1.8 \\ 1.8 & 1.9 & 1.8 & 1.8 & 1.8 & 1.9 \\ 1.9 & 1.9 & 1.9 & 1.8 & 1.8 & 1.9 \\ 1.7 & 1.7 & 1.8 & 1.6 & 1.5 & 1.6 \\ 1.6 & 1.3 & 1.4 & 1.6 & 1.3 & 1.5 \\ 1.7 & 1.5 & 1.5 & 1.6 & 1.3 & 1.5 \\ 1.6 & 1.4 & 1.3 & 1.2 & 1.1 & 0.9\end{array}$

$\begin{array}{llllll}1.6 & 1.8 & 1.8 & 1.6 & 1.4 & 1.5 \\ 1.5 & 1.5 & 1.5 & 1.5 . & 1.3 & 1.4 \\ 1.5 & 1.5 & 1.5 & 1.4 & 1.3 & 1.4 \\ 1.4 & 1.5 & 1.6 & 1.5 & 1.2 & 1.5\end{array}$

E. EMPLOYMENT AND ADVANCEMENT
1. find job
$1.5 \quad 1.1$
$\begin{array}{llll}1.3 & 0.8 & 0.9 & 0.9\end{array}$
2. advance in job
1.10 .9
$\begin{array}{llll}1.1 & 0.6 & 0.6 & 0.6\end{array}$
3. secondary education
$0.7 \quad 0.4$
$0.7 \quad 0.6$
$0.6 \quad 0.5$
4. resumé
$\begin{array}{ll}1.6 & 1.5\end{array}$
$1.6 \quad 1.3$
$\begin{array}{ll}1.2 & 1.4\end{array}$
5. make more money
1.10 .9
1.1
0.7
$0.7 \quad 0.6$ 
with the exception of talking to children and grandchildren. The exception was age related ( $82 \%$ over the age of 45$)$. Table 4 exhibits that this particular need is greater among older participants learning English.

\section{Education Level}

In general, education level and motivations for learning English did not appear connected (see Table 4). Nonetheless, there were very slight differences among college educated learners $(7 \%)$ in a number of indicators. Participants with college education indicated a lower interest in linguistic needs such as reading, vocabulary acquisition, or pronunciation. This is due to most already having more than 10 years of English language training at school. Language teaching in Chinese schools emphasizes reading, vocabulary acquisition, and pronunciation. Therefore, college educated respondents were less concerned about these particular linguistic needs.

Similarly, the need for learning English to ride public transportation, shop, use the postal system, fill out forms, make friends with Canadians, know Canadian festivals, talk to children (or grandchildren) and neighbours is less important for college educated participants since they have enough English to perform simple everyday routines. However, the mean score for reading English newspapers and conversing at parties was highest for college educated participants. This is perhaps because these participants are more curious and receptive to new ideas and people outside of their culture. Reading newspaper and interacting with other Canadians provide an opportunity to know Canada.

Age

No significant differences were found in regard to the relationship between age and motivations (see Table 5) among speaking, listening, reading, vocabulary, pronunciation, riding public transportation, shopping, seeking help, making phone calls, travelling on own, learning about Canada, knowing Canadian festivals and neighbours. However, writing, banking, using the postal system, filling out forms, watching TV or movies, listening to radio, reading newspapers, making friends with Canadians, knowing Canadian customs, conversing at parties, talking to children and grandchildren, visiting and talking to Canadians, and employment and advancement factors are age related. The connection is inverse: the higher the age, the lower the mean (or the mean remained constant) except for talking to childern and grandchildren. The exception was due to older people being more likely to have older children or non-bilingual grandchildren. Of the participants, $44 \%$ were at or approaching retirement age. Hence, they were less interested in seeking employment and advance- 
Survey Analysis-selection criteria: Education Level

\begin{tabular}{|c|c|c|c|c|c|c|}
\hline \multirow{3}{*}{ number } & grade range & $1-3$ & $4-6$ & $7-9$ & $\underline{10-12}$ & $13+$ \\
\hline & $\mathrm{T}: 497$ & 97 & 165 & 145 & 57 & 33 \\
\hline & percent & $20 \%$ & $29 \%$ & $33 \%$ & $12 \%$ & $7 \%$ \\
\hline
\end{tabular}

A. LINGUISTIC NEEDS

$\begin{array}{llllll}\text { 1. speaking } & 2.0 & 1.9 & 2.0 & 2.0 & 2.0 \\ \text { 2. listening } & 2.0 & 1.9 & 1.9 & 2.0 & 2.0 \\ \text { 3. reading } & 1.6 & 1.7 & 1.7 & 1.7 & 1.5 \\ \text { 4. writing } & 1.4 & 1.3 & 1.4 & 1.4 & 1.4 \\ \text { 5. vocabulary } & 1.6 & 1.7 & 1.6 & 1.6 & 1.4 \\ \text { 6. pronunciation } & 1.7 & 1.7 & 1.7 & 2.0 & 1.5\end{array}$

B. BASIC SKILLS

$\begin{array}{llllll}\text { 1. ride public trans. } & 1.6 & 1.9 & 1.8 & 1.6 & 1.4\end{array}$

$\begin{array}{llllll}\text { 2. shopping } & 1.6 & 1.8 & 1.8 & 1.7 & 1.5\end{array}$

$\begin{array}{llllll}\text { 3. banking } & 1.7 & 1.7 & 1.8 & 1.7 & 1.7\end{array}$

$\begin{array}{llllll}\text { 4. postal system } & 1.6 & 1.6 & 1.7 & 1.6 & 1.5\end{array}$

$\begin{array}{llllll}\text { 5. seek help } & 1.7 & 1.8 & 1.9 & 1.8 & 1.8\end{array}$

$\begin{array}{llllll}\text { 6. phone calls } & 1.8 & 1.8 & 1.9 & 1.8 & 1.8\end{array}$

$\begin{array}{llllll}\text { 7. forms } & 1.7 & 1.6 & 1.8 & 1.7 & 1.6\end{array}$

$\begin{array}{llllll}\text { 8. travel on own } & 1.5 & 1.5 & 1.5 & 1.4 & 1.5\end{array}$

$\begin{array}{lllllll}\text { 9. TV, radio, movies } & 1.7 & 1.4 & 1.6 & 1.7 & 1.8\end{array}$

$\begin{array}{llllll}\text { 10. newspapers } & 1.7 & 1.0 & 1.4 & 1.6 & 1.8\end{array}$

C. CULTURAL AWARENESS

$\begin{array}{llllll}\text { 1. learn about Canada } & 1.7 & 1.6 & 1.7 & 1.6 & 1.7 \\ \text { 2. friends with Canadians } & 1.4 & 1.4 & 1.5 & 1.5 & 1.3 \\ \text { 3. Canadian festivals } & 1.4 & 1.4 & 1.5 & 1.4 & 1.2 \\ \text { 4. Canadian customs } & 1.5 & 1.4 & 1.5 & 1.4 & 1.4\end{array}$

D. SOCIAL INTERACTION

$\begin{array}{llllll}\text { 1. children } & 1.3 & 1.7 & 1.4 & 1.4 & 1.1 \\ \text { 2. neighbours } & 1.6 & 1.6 & 1.7 & 1.6 & 1.4 \\ \text { 3. parties } & 1.3 & 0.9 & 1.2 & 1.3 & 1.4 \\ \text { 4. visit Canadians } & 1.3 & 1.0 & 1.2 & 1.2 & 1.2\end{array}$

E. EMPLOYMENT AND ADVANCEMENT

$\begin{array}{llllll}\text { 1. find job } & 1.3 & 0.8 & 1.1 & 1.4 & 1.3 \\ \text { 2. advance in job } & 1.1 & 0.6 & 0.9 & 1.1 & 1.0 \\ \text { 3. secondary education } & 0.9 & 0.4 & 0.5 & 0.9 & 0.9 \\ \text { 4. make more money } & 1.1 & 0.7 & 0.9 & 1.1 & 0.9 \\ \text { 5. resumé } & 1.6 & 1.3 & 1.6 & 1.7 & 1.3\end{array}$


Table 5

Survey Analysis-selection criteria: Age

\begin{tabular}{|c|c|c|c|c|c|}
\hline \multirow{3}{*}{ number } & age groups & $17-29$ & $30-44$ & 45-59 & $60+$ \\
\hline & $T: 457$ & 15 & 64 & 175 & 203 \\
\hline & percent & $3 \%$ & $14 \%$ & $38 \%$ & 44 \\
\hline
\end{tabular}

A. LINGUISTIC NEEDS

$\begin{array}{lllll}\text { 1. speaking } & 2.0 & 2.0 & 2.0 & 1.9 \\ \text { 2. listening } & 2.0 & 2.0 & 1.9 & 1.9 \\ \text { 3. reading } & 1.8 & 1.8 & 1.7 & 1.6 \\ \text { 4. writing } & 1.7 & 1.5 & 1.4 & 1.3 \\ \text { 5. vocabulary } & 1.8 & 1.7 & 1.6 & 1.6 \\ \text { 6. pronunciation } & 1.7 & 1.7 & 1.7 & 1.7\end{array}$

B. BASIC SKILLS

1. ride public trans.

$\begin{array}{llll}1.7 & 1.7 & 1.8 & 1.8\end{array}$

2. shopping

$\begin{array}{ll}1.8 & 1.7\end{array}$

1.8

1.7

3. banking

1.9

1.8

1.6

4. postal system

1.7

1.7

1.5

5. seek help

1.9

1.7

1.8

6. phone calls

$1.9 \quad 2.0$

1.7

1.6

1.8

7. forms

1.9

1.5

1.8

1.5

8. travel on own

1.7

1.5

1.8

1.5

9. $\mathrm{TV}$, radio, movies

1.9

1.7

1.4

1.4

10. newspapers

1.8

1.6

1.5

1.0

C. CULTURAL AWARENESS

1. learn about Canada

$\begin{array}{ll}1.7 & 1.8\end{array}$

$1.7 \quad 1.7$

1.5

2. friends with Canadians

1.7
1.4

1.7

1.4

3. Canadian festivals

1.4

1.5

1.4

4. Canadian customs

1.8

1.5

1.5

1.4

D. SOCIAL INTERACTION

$\begin{array}{lllll}\text { 1. children } & 0.9 & 1.4 & 1.4 & 1.5 \\ \text { 2. neighbours } & 1.7 & 1.6 & 1.6 & 1.6 \\ \text { 3. parties } & 1.7 & 1.3 & 1.0 & 1.0 \\ \text { 4. visit Canadians } & 1.9 & 1.3 & 1.0 & 1.0\end{array}$

E. EMPLOYMENT AND ADVANCEMENT

$\begin{array}{lllll}\text { 1. find job } & 2.0 & 1.8 & 1.0 & 0.6 \\ \text { 2. advance in job } & 1.7 & 1.7 & 0.8 & 0.5 \\ \text { 3. secondary education } & 1.2 & 0.9 & 0.4 & 0.4 \\ \text { 4. resumé } & 1.8 & 1.7 & 1.5 & 1.2 \\ \text { 5. make more money } & 1.3 & 1.5 & 0.8 & 0.5\end{array}$


ment and probably depended on adult children to assist them in carrying out certain essential activities.

\section{Other Motivations}

On the questionnaire, three blank spaces were provided for the participants to fill out any other motives for learning English. 22 participants indicated that learning English to speak to their physician was "very important."

\section{Conclusion}

What motivates the adult Chinese immigrant who attends ESL classes? The results of the study suggest that the motives of adult Chinese immigrants attending ESL classes include all basic linguistic needs, basic skills (except reading newspapers), cultural awareness, social interaction (except conversing at parties and visiting Canadians), and writing resumés.

Do perceived motivations differ according to age, education level, and length of residence in Canada? Contrary to general assumptions that motivation to learn differs according to these factors, this study finds there are no significant differences among most of the indicators in these regards. However, there are slight differences among some indicators. For example, older participants are less concerned about employment and advancement, and college educated participants show less need for learning to read, acquiring vocabulary, etc.

What are the implications of the results of the study for ESL teaching? Based on the results of this study, the writer would like to make the following recommendations in regard to the ESL programme at CICS and other similar institutions. First, teaching objectives at CICS should include both the teaching of English and Canadian culture. The teaching of English should focus on language needed for conducting everyday life (basic skills) and social interaction. All four language skills: speaking, listening, reading, and writing should be taught at the same time with more emphasis on the first three skills. Pronunciation and vocabulary teaching is also necessary.

Learning Canadian culture is clearly important to adult Chinese ESL learners. Linguistic needs and basic skills supercede cultural awareness in importance, but cultural awareness is given priority over social interaction and employment and advancement. Within this category, the mean for learning about Canadian geography, history and laws was slightly above the grand mean value, and learning about Canadian festivals and social customs and making friends with Canadians was slightly below the grand mean. All fell within the value range: "important." 
$82 \%$ of ESL learners at CICS are over 45 years of age. Meeting the needs of this predominant age group is very important for the instructor. Instructors tend to attempt to satisfy the needs of the majority, in this case, older learners. This creates problems for younger adult learners whose needs often remain unmet, and the pace of teaching tends to be too slow for them (based on personal teaching experience). Perhaps separate classes are needed for young adults whose primary needs are access to employment and advancement.

Lastly, this study also reveals demographic characteristics of adult education participants. The survey confirms the findings of Dickinson and Verner (1977) Devereaux (1984), and Davie (1986) that most adult learners are female. But contrary to their findings, this study shows that (1) there are more older participants ( $82 \%$ are 45 or over) than younger participants (17\% are under 44$)$, and (2) the majority of the participants (82\%) have less than Grade 10 education. This study also confirms Dickinson and Verner's (1977) findings that those who have lived in the country for a longer period are more active participants in adult education; e.g., $62 \%$ of the participants have been here for more than 2 years.

The data does provide some insights into the motivations of adult Chinese learners in attending ESL classes. Since the survey represents approximately one-third of the ESL participants in Metro Toronto, ESL coordinators, instructors, and curriculum writers who are working with adult Chinese immigrants may find the study of value to their programme planning and curriculum design. 


\section{APPENDIX \\ Motivations for Studying English}

Please circle the appropriate numbers to indicate your response to the questions by using the following scale.
1. important
2. somewhat important
3. not important

A. In studying English, I am interested in

$$
\begin{aligned}
& \text { speaking } \\
& \text { listening } \\
& \text { reading } \\
& \text { writing } \\
& \text { grammar } \\
& \text { vocabulary } \\
& \text { pronunciation }
\end{aligned}
$$

\begin{tabular}{lll}
\multicolumn{3}{c}{ importance } \\
& 2 & 3 \\
1 & 2 & 3 \\
1 & 2 & 3 \\
1 & 2 & 3 \\
1 & 2 & 3 \\
1 & 2 & 3 \\
1 & 2 & 3
\end{tabular}

B. I would like this course to help me

to ride subways and buses
to shop
to use a bank
to use the mail system
to ask directions or seek help
to make phone calls
to fill out forms
to write resumés
to learn about Canada
(geography, history, laws, etc.)
to make friends with Canadians
to learn about Canadian festivals
to know Canadian social customs
to talk to my children and grandchildren
to talk to neighbours, workmates
to converse at parties
to be able to visit other Canadians
to find a job
to advance in my job or get a better one
to attend a college or university
to travel on my own (take airplane)
to watch TV or movies, listen to radio
to read newspapers, magazines
to make more money

$\begin{array}{lll}1 & 2 & 3 \\ 1 & 2 & 3 \\ 1 & 2 & 3 \\ 1 & 2 & 3 \\ 1 & 2 & 3 \\ 1 & 2 & 3 \\ 1 & 2 & 3 \\ 1 & 2 & 3 \\ 1 & 2 & 3 \\ & & \\ 1 & 2 & 3 \\ 1 & 2 & 3 \\ 1 & 2 & 3 \\ 1 & 2 & 3 \\ 1 & 2 & 3 \\ 1 & 2 & 3 \\ 1 & 2 & 3 \\ 1 & 2 & 3 \\ 1 & 2 & 3 \\ 1 & 2 & 3 \\ 1 & 2 & 3 \\ 1 & 2 & 3 \\ 1 & 2 & 3 \\ 1 & 2 & 3 \\ 1 & 2 & 3 \\ 1 & 2 & 3 \\ 1 & 2 & 3\end{array}$




\section{REFERENCES}

Anisfeld, Moshe, and W. E., Lambert. (1961). Social and psychological variables in learning Hebrew. Journal of Abnormal and Social Psychology, 63, 524-529.

Beatty, C. J., and J. J. Chan. (1984). Chinese scholars abroad: changes in perceived academic needs. The ESP Journal, 3, 53-59.

Brundage, Donald H., and Dorothy Mackeracher. (1980). Adult Learning Principles and Their Application to Program Planning. Ontario: The Ministry of Education.

Clément, Richard et al, (1977). Motivational variables in second language acquisition: A study of Francophones learning English. Canadian Journal of Behaviourial Science, 9(2), 123-133.

Davie, L. E. (1986). Patterns of participation in adult education in Ontario. Canadian Journal of University Continuing Education, 12(1), 47-68.

Devereaux, M. S. (1984). One in Every Five: A Survey of Adult Education in Canada. Ottawa: Minister of Supply and Services Canada.

Dickinson, Gary. and Coolie Verner. (1977). Learning Opportunities for Adults. Paris: Organization for Economic co-operation and Development, 4, 76-109.

Gardner, R. C., and W. E. Lambert. (1972). Attitudes and Motivation in Second Language Learning. Rowley, Mass.: Newbury House Publishers.

Kidd, J. R. (1959). How Adults Learn. New York: Association Press.

Lambert, W. E. et al. (1972). Attitudinal and cognitive aspects of intensive study of a second language. In R. C. Gardner and W. E. Lambert (Eds.) Attitudes and Motivation in Second Language-Learning. Rowley, Mass.: Newbury House Publishers.

Ostler, S. E. (1980). A survey of academic needs for advanced ESL. TESOL Quarterly, 14 (4), 489-502.

Schumann, John H. (1975). Affective factors and the problem of age in second language acquisition. Language Learning, 25(2), 209-235.

Stern, H. H. (1983). Fundamental Concepts of Language Teaching. Oxford. Oxford University Press.

Sun, Yilin. (1987). An EFL needs assessment: Chinese students at a Canadian university. TESL Canada Journal, 5(1), 27-44

Wlokowski, R. J. (1985). Enhancing Adult Motivation to Learn. San Francisco: Jossey-Bass.

\section{THE AUTHOR}

Li Chuang Paper is a graduate student in the Department of Curriculum (Modern Language Center) at the Ontario Institute for Studies in Education. She teaches ESL at Chinese Information and Community Services. Her research interests include comparative cultures (Canada and China), culture and language, and curriculum design. 